\title{
DESPLAZADAS POR LA GUERRA ESTADO, GÉNERO Y VIOLENCIA EN LA REGIÓN TRIQUI. DE MARINIS, NATALIA. MÉXICO, D. F.: EDITORIAL CASA CHATA, CIESAS, 2019
}

\author{
Dolores Figueroa Romero \\ Consejo Nacional de Ciencia y Tecnología, \\ Ciudad de México, México
}

Recibido: 14/04/2020 - Aceptado: 18/04/2020

El libro de Natalia De Marinis es emblemático para pensar críticamente sobre procesos y contextos en los que la violencia política del Estado se ensaña contra pueblos indígenas en resistencia y afecta de manera particular a mujeres, niños y ancianos. De Marinis analiza un caso acontecido en San Juan Copala, una población indígena en la región triqui de la mixteca oaxaqueña en México, donde se dio el asesinato de más de treinta personas y el desplazamiento forzado de 150 familias entre el 2009 y 2010. ${ }^{1} \mathrm{El}$ desplazamiento fue consecuencia directa de la represión paramilitar que experimentaron los comunitarios de San Juan Copala por proclamar su municipio autónomo y libre.

La literatura académica sobre pueblos indígenas y el Estado mexicano es acuciosa en reflexionar sobre los hitos históricos en el reconocimiento de los derechos de los pueblos indígenas -y ahora los retrocesos-, así como en los procesos de lucha y resistencia en distintos contextos y regiones (Hernández et al.; Bastos y Sierra). De Marinis escribe a contrapelo y contraviniendo las recurrentes miradas a los procesos que son exitosos y emblemáticos de la lucha de los pueblos por la autonomía; ella opta por el análisis localizado y etnográfico de un pequeño experimento autónomo y de la violencia estatal (y no estatal) que reprimió a los hombres y las mujeres de San Juan Copala que buscaban ejercer su derecho legítimo a autogobernarse.

En el 2007 los líderes de San Juan Copala proclamaron su municipio autónomo, el único municipio autodeclarado autónomo en Oaxaca y fuera de Chiapas. ${ }^{2}$ Este pequeño experimento político empezó a generar esperanza, tranquilidad y paz con el impulso de líderes no guerreros y con la participación de mujeres dignas y valientes. No obstante, como ya dije, este experimento no terminó bien, pues fue abortado desde adentro y desde afuera.

De Marinis nos hace ver cómo la violencia del Estado que se manifiesta en los márgenes (empleando el enfoque de Das y Poole), en los territorios donde, por medio 
de imaginarios de extrañeza, otredad y salvajismo, se justifica el despojo y la arbitrariedad sin casi ningún costo político para los poderosos. La autora habla de la construcción de un Estado tardío -Estado priísita ${ }^{3}$ en Oaxaca- en territorios alejados, empobrecidos y exotizados. Ahí la violencia pareciera anidar desde siempre, desde inicio de la avaricia colonial blanca y mestiza.

El libro muestra los mecanismos de represión atomizados en decenas de actores e instituciones que a nivel local controlan y aterrorizan en la región Triqui. Es también un libro con una mirada feminista y etnográfica que da cuenta de los testimonio y reflexiones de las mujeres en resistencia, de las mujeres desplazadas que con su tesón y preocupación se convirtieron en los pilares fundamentales de la resistencia de las familias que apoyaban el proyecto de autonomía (De Marinis 248).

De Marinis tiene la fabulosa habilidad para tejer múltiples formas de enunciar, articular y plantear sus preocupaciones analíticas derivadas en diálogo con los propios actores y víctimas de los procesos. La leo y encuentro en su manera de introducirnos en la problemática de la región Triqui un muy cuidadoso acercamiento que transporta poderosamente a otros escenarios donde he leído sobre el mismo drama humano. Lo reconozco.

Justo en la introducción, De Marinis muestra cómo los pobladores triquis nombran el problema que los aqueja: "Zaniuúa" significa "guerra" o "problema" en triqui. Es decir, la violencia a esas tierras llegó por la modernización (década de 1940), la militarización (1960) y la politiquería partidista (1990) que envició las lógicas de poder local. Los testimonios ampliamente citados en el libro explican que "la guerra en la región triqui" significa persecución, asesinato, represión y terror, pero también pobreza, miedo, aislamiento, incomprensión e invisibilidad. La invisibilidad fue en cuanto al sufrimiento social causado por la muerte violenta (¿Por qué Edgar? Un niño de 8 años asesinado por una bala perdida cuando caminaba por las calles de su pueblo) (De Marinis 158). Es la invisibilidad del sufrimiento social causado por el desplazamiento forzado a cuenta gotas; es el sufrimiento causado por las formas perversas en las cuales el Estado "inocula" dosis de violencia para matar la resistencia local (De Marinis 158).

Zaniuúa en triqui me recuerda el título del informe elaborado por CIDCA (Centro de documentación e investigación de la Costa Atlántica de Nicaragua) en 1984 para dar cuenta de las graves violaciones a los derechos humanos al pueblo miskito durante el conflicto contrarrevolucionario en Nicaragua: Trabil Nani: Historical Background and Current Situation of the Atlantic Coast of Nicaragua. "Trabil nani" significa "muchos problemas... muchos problemas". Así externaba una anciana miskita, lamentándose en un taller con el equipo de investigadores del CIDCA, sobre los problemas derivados de la presencia militar de sandinistas en la región de río Coco o río Wangki -como le dicen los pobladores indígenas-. El río Coco es caudaloso y 
hace de frontera natural entre Honduras y Nicaragua; es hogar de cientos de comunidades indígenas miskitas que al inicio de la guerra contrarrevolucionaria fueron desplazadas forzosamente de sus territorios.

En las riberas del río Coco empezó la rebelión armada indígena en contra de la incorporación indígena -miskita- al proceso revolucionario sandinista. Durante la guerra, hubo dos procesos de desplazamiento forzado de familias: en 1982, treinta y nueve comunidades (8500 miskitos) fueron llevados forzadamente -y sin su conocimiento- al campamento Tasba Pri en el centro norte de Nicaragua (González). El segundo desplazamiento fue de 4000 miskitos y mayagnas que fueron llevados a zonas de producción en Jinotega y Matagalpa (López y Rivas).

La composición de las familias desplazadas fue de mujeres jóvenes, adultas, ancianos y niños, ya que los hombres y los pastores se habían ido a las montañas a unirse a las fuerzas rebeldes de Honduras. Los comunitarios les llamaban a los enmontañados los "buay nani", los muchachos. Los chicos armados de la montaña emulan la figura de los guerreros triquis, es decir, jóvenes de masculinidades violentas que, sin duda, también forman parte de las historias y trayectorias de resistencias de los pueblos.

¿Por qué mi relato se detiene en encontrar elementos comparativos entre dos experiencias de desplazamiento forzado en Nicaragua y México? Porque el libro de De Marinis me lleva a pensar en procesos similares en ambos países en función de tres ejes analíticos:

\section{Para el análisis de la violencia política contra pueblos indígenas a los márgenes} del Estado. De Marinis cuenta que el aparato ideológico que justifica el despojo e intervención mediante tecnologías (violentas) de seguridad en la región Triqui estuvieron acompañados por una mirada estigmatizante hacia el pueblo triqui. La represión contemporánea de los comunitarios proautonomía es parte y resultado de un continuo histórico de larga data donde el Estado y las elites oaxaqueñas han construido la otredad indígena triqui para justificar su dominación, persecución subordinación por todos los medios posibles. La mirada estigmatizante sobre los triquis los describe como naturalmente violentos, borrachos y sediciosos; poco maleables al proyecto modernizador y por lo mismo siempre sospechosos de desacato, aunque ambivalentemente útiles para el enriquecimiento ilícito y la implementación de canales de control clientelar.

La mirada estatal que dispara la racialización de lo indígena al punto de despojarlo de su humanidad está presente en el lenguaje de inteligencia militar sandinista sobre la población miskita (Blandón Guevara; CIDCA). Los indígenas rápidamente fueron percibidos como enemigos internos de la revolución, lejanos cultural y políticamente del proyecto revolucionario y de la nación nicaragüense. "Esos Moskos son malos... son mentirosos y antirrevolucionarios e imperialistas" (Davis, 2000). Los relatos militares 
cuentan -en las memorias de jefes militares trasnochados- que el operativo Navidad Roja fue llevado a cabo por ocho ballatones de soldados traídos del pacífico para evacuar a la población indígena de las orillas del río (Davis et al., 2007; Blandón Guevara). Los soldados nunca habían estado en la costa Atlántica y, por supuesto, no hablaban miskito. Fueron acompañados en algunos puntos por costeños indígenas hablantes, pero ello no evitó que la misión fuera violenta, racista y con mutuo extrañamiento.

Recalco la idea del mutuo extrañamiento para nombrar la relación tensa entre los proyectos de la izquierda de transformación revolucionaria y los movimientos indígenas. En el caso nicaragüense, los sandinistas actuaban en función de un plan para transformar la sociedad -visto y concebido desde la izquierda marxista-, que no fue sensible a las aspiraciones y las formas de vida indígenas (Mallón; Grandin). La eliminación física del enemigo interno fue justificable para la obtención del bien mayor que era la defensa de la revolución.

En el caso del proyecto modernizador priísta en la región Triqui, hay muchos elementos por mencionar. Los triquis, de todos los pueblos indígenas de Oaxaca, eran tenidos por el gobierno como los más salvajes, "los otros de los otros", bárbaros, exóticos, monolingües, poco maleables, poco propensos a moldearse a los modos mestizos. Estaban ubicados siempre al margen de lo racional, eran habitantes de territorios aislados, fueron objeto ideal de despojo y agresión. La circulación de armas, alcohol y privilegios clientelares fueron los hilos de control que hicieron de la pobreza el caldo ideal para mostrar a la región maldecida por una violencia irracional, intraétnica e intracomunitaria.

De Marinis dice que la militarización de la Triqui fue una pieza clave para fortalecer las relaciones desiguales de mestizos y tiquis, pues significó el establecimiento de un control territorial que aseguró el encubrimiento para los caciques a fin cometer abusos, la inseguridad para la población de transitar el territorio y la represión selectiva de líderes rebeldes (De Marinis 85). La presencia militar -al igual que en la costa Atlánticaorquestó una seguridad ficticia que, lejos de proteger a la población local, aseguró la presencia de instituciones externas para ejercer dominación y gobernabilidad hasta los niveles más micros.

2. El segundo eje de análisis es el desplazamiento forzado y las líneas divisorias del género. En ambos casos aquí tratados, las víctimas de desplazamiento forzado fueron mayoritariamente mujeres indígenas, niños y ancianos. Para el caso costeño las desplazadas del río Coco fueron los que se quedaron atrás en las comunidades resguardando la casa, los animales, los enseres, mientras que los hombres jóvenes y pastores moravos habían huido a Honduras.

Las líneas del impacto de la guerra claramente segmentaron a la población por género y geografías de terror y seguridad. Según el gobierno, la razón principal para 
sacar a la población indígena fue para resguardarlos de posibles ataques de la insurgencia armada (Jenkins). Sin embargo, versiones vertidas en documentos de inteligencia afirman que otro objetivo de la operación fue eliminar la base social de los indígenas en armas y extirpar el tejido comunitario al cual ellos pertenecían. La distancia y la incertidumbre de no saber dónde estaba cada uno -unos en Tasba Pri y otros en la montañamermó tanto como las propias bajas de muerte.

Las experiencias de desplazamiento, en el caso de De Marinis, fue un proceso diferente al nicaragüense, pues no se trató de un desplazamiento colectivo en jalón, sino a cuenta gotas y por un lapso extenso. Las personas desplazadas de San Juan Copala fueron expulsadas poco a poco de su comunidad por terror instalado en su propia casa. No fueron llevados al monte, sino que ellos mismos buscaron cómo huir, a escondidas, en la obscuridad de la madrugada. Algunos fueron acogidos en comunidades aledañas, otros llegaron a Oaxaca y otros añejos llegaron a la Ciudad de México.

Todos buscaban un espacio, un lugar donde no ser perseguidos, subsistir y esperar a saber de los seres queridos para después tatar de regresar. Natalia De Marinis, en su libro, de manera muy diligente reconstruye los testimonios de ellas, las desplazadas, las que cuando llegaron a Oaxaca empezaron hacer recuento de lo vivido, de lo llorado y de lo perdido. Había tristeza por los muertos que quedaron atrás y por la incertidumbre de no saber qué pasaría. De Marinis estuvo ahí para oírlas y para hacer visible el dolor, la angustia y la mirada inquietante hacia el futuro, desde el horizonte de posibilidades que las mujeres indígenas tienen en ese país. El libro de Natalia visibiliza los testimonios como prueba de lo que pasó y que tuvo secuelas.

Estudios y novelas sobre los impactos psicosociales de la guerra entre la población indígena en Nicaragua hasta ahora se están escribiendo. El rescate de la memoria es una tarea pendiente que se lleva a cabo con dificultad y a cuenta gotas. Al trauma por la guerra le llaman en miskito "siran" y sigue ahí, abierto y sin sanar. Los hombres tocados por el siran de la guerra se alcoholizan y ¿las mujeres? ¿Qué hacen ellas? ¿Dónde están sus comunidades? ¿Qué pasó con ellas después de tantos años? (Davis et al., 2007).

3. El tercer eje de análisis es el rol de las mujeres para generar procesos de diálogo, de resistencia, de cuido, denuncia y politización de su experiencia de dolor. Una de las partes más esperanzadoras del texto de De Marinis es el tratamiento de la agencia de las mujeres triquis, sus formas de resiliencia, de aprendizaje político y su entereza para estar ahí luchando, cocinando, cuidando de otros, poniendo el cuerpo para la lucha, hablando en los silencios y comunicando con los gestos. “Las mujeres son los pilares fundamentales de la resistencia de las familias" (De Marinis 248).

De Marinis deja ver que la resistencia política de los pueblos pasa por el hogar, por el involucramiento y la voluntad de todos, pero sobre todo de las mujeres, de los 
hijos que dan continuidad a la vida y a la comunidad. Los líderes por el municipio autonómo les pedían a las mujeres resistir, quedarse en las plazas públicas y en la comunidad, a pesar del ataque de los paramilitares y del maltrato e indiferencia de las autoridades del estado. La cara más visible de la resistencia triqui fueron ellas. Ingrato sería del movimiento indígena no reconocer el sacrificio de sus mujeres.

Las lideresas triquis como Sol o Luz se hicieron en el plantón, a fuerzas de hablar en público, en adiestrarse en articular respuestas para los periodistas que querían saber de lo ocurrido y sobre todo conocer por boca de las víctimas las razones de la violencia. Todo se tradujo en la politización de su experiencia. Las mujeres desplazadas, ya siendo desplazadas, empezaron a conocer sobre la autonomía, sobre una política que iba más allá de San Juan Copala. Fue un proyecto de resistencia indígena que englobaba no solo a los triquis de la mixteca baja, sino a todos los pueblos indígenas de México. Sopesar esa responsabilidad y la escala de los significados políticos de su actuar no fue sencillo, según nos cuenta De Marinis.

\section{¿Qué podemos decir a la luz del drama de las mujeres triquis sobre la autonomía con ojos de mujer?}

Podemos decir que, en el caso de la experiencia de San Juan Copala, la autonomía fue un respiro para detener la violencia fratricida, interclánica, donde la expectativa de cambio y paz inspiró el proyecto de una radio comunitaria y la enseñanza de nuevos valores políticos y de convivencia. Líderes pacíficos y no guerrilleros que, en vez de usar las armas y amedrentar con la fuerza, buscaron el bien de todas las personas. La autonomía fue una oportunidad para convocar a la construcción de nuevas masculinidades $\mathrm{o}$, por lo menos, de renegar de las violentas.

He tratado de entender mejor el rol de las mujeres miskitas en la consolidación de la paz en la costa atlántica y al hacerlo las conocí en su rol de negociadoras, porque se quedaron atrás solas y dolientes. Esa condición de duelo las hizo acercarse para convencer a mandos medios militares sandinistas de entablar pláticas y acercamientos de paz con líderes de la resistencia miskita que, a su vez, estaban ya agotados por el conflicto. Las negociaciones de paz y las consultas para la autonomía en Nicaragua fueron producto a nivel local y regional del buen oficio de las mujeres.

Lo que pasó después, las leyes y la institucionalización del régimen de autonomía multiétnica fue cosa de los hombres. Nicaragua me enseñó que la autonomía política es cosa de hombres y la autonomía de la paz es de las mujeres (Figueroa; Figueroa y Barbeyto). Debido a estos oficios de paz y de la entrega desinteresada, celebro la publicación del libro de De Marinis que honra y visibiliza la participación de las mujeres en la vida política de sus comunidades, lo cual nos deja lecciones humanas inobjetables. 


\section{Notas}

1 San Juan Copala es uno de los tantos municipios que componen la región baja de la mixteca oaxaqueña, subregión montañosa al noreste del estado mexicano de Oaxaca. El pueblo indígena Triqui es uno de los 18 grupos étnicos que habitan en Oaxaca. La región Triqui se ubica en el noroeste del estado y se divide en la Triqui "alta", cuyo centro es Chicahuaxtla; la Triqui "media", cuyo centro es Itunyoso; y la Triqui "baja", cuyo centro es San Juan Copala. Su población total es de cerca de 13000 habitantes. Específicamente en la región Triqui baja hay 30 comunidades (De Marinis 24).

2 La referencia comparativa con Chiapas intenta poner en perspectiva la experiencia de lucha autonómica municipal en Oaxaca con el levantamiento neozapatista en 1994 de los indígenas mayas del estado de Chiapas que iniciaron un proceso de autodeterminación indígena que ha sido ampliamente conocido y documentado.

3 Priísta se refiere al Partido de la Revolución Institucional (PRI), partido político mexicano que gobernó de manera hegemónica el país en la era posrevolucionaria y nacionalista de México. El PRI tuvo la gran habilidad de crear estructuras partidarias regionales integrando de manera funcional y efectiva a cacicazgos locales rurales y campesinos.

\section{Bibliografía}

Bastos, Santiago y Sierra, María Teresa. (Coords.). Estado y pueblos indígenas en México. La disputa por la justicia y los derechos. Colección México. México: CIESAS, 2017.

CIDCA. Trabil Nani: Historical Background and Current Situation of the Atlantic Coast. 1984.

Blandón Guevara, Erick. Vuelo de cuervos. España: Alfaguara, 2017.

Das, Veena y Deborah Poole. "State and its Margins: Comparative Ethnographies". Anthropology in the Margins of the State. Eds. Veena Das y Deborah Poole. Santa Fe: SAR Press, 2004. 3-33.

Davis, Sandra et al. Las mujeres valientes del Wangki Awala. Reconstruyendo nuestras almas y esperanzas. Nicaragua: Horizonte 3000, 2007.

Davis, Sandra et al. Wangki Awala: Nuestra memoria de la guerra para vivir en paz. Nicaragua: URACCAN-EED, 2000.

Figueroa, Dolores. Miskitu Women and Their Social Contribution to the Regional Politics of the Atlantic Coast of Nicaragua. AlterNative: An International Journal of Indigenous Peoples, 8, 4 (2012): 447-465.

Figueroa, Dolores y Arelly Barbeyto. Strong Women: Memories of Miskitu Women Forging Peace and Autonomy. Indigenous Struggles for Autonomy. The Caribbean 
Coast of Nicaragua. Aut. Luciano Baracco. New York-Londres: Lexington Books, 2019, 155-180.

González Pérez, Miguel. Gobiernos pluri-étnicos: la constitución de regiones autónomas en Nicaragua. México: Plaza y Valdes-URACCAN, 1997.

Grandin, G. Living in Revolutionary Time. Coming to Terms with the Violence of Latin America's Long Cold War. A Century of Revolution. Insurgent and Counterinsurgent Violence During Latin America's Long Cold War. Eds. G Grandin y G. M. Joseph. Durham y Londres: Duke University Press, 2010. 1-42.

Hernández, Rosalva Aída et al. Cord. El Estado en tiempos del PAN: neoindigenismo, legalidad e identidad. México: CIESAS, 2004.

Jenkins, Jorge. El desafío indígena en Nicaragua. El caso de los Miskitu. Managua: Editorial Vanguardia, 1986.

López y Rivas, Gilberto. Los guerreros de la revolución sandinista. La Jornada. 12 de septiembre de 2014.

Mallón, F. E. Beyond Colonialism: Race and Ethnicity in the Mobilization of Indigenous People. LASAFORUM. XLVIII/2 (2017): 17-18.

Dolores Figueroa Romero. Mexicana. Doctora en Sociología por la Universidad de York, Canadá. Catedrática en el Consejo Nacional de Ciencia y Tecnología (CONACIT) y en el Centro de Investigación y Estudios Superiores en Antropología Social (CIESAS), en la Ciudad de México.

Contacto: dolores.figueroa@ciesas.edu.mx

ORCID: https://orcid.org/0000-0001-7038-8301 